\title{
Existence and multiplicity of solutions for second-order impulsive differential equations on the half-line
}

\author{
Lizhao Yan ${ }^{1,2}$, Jian Liü ${ }^{3 *}$ and Zhiguo Luo²
}

"Correspondence: ljorg@126.com

${ }^{3}$ School of Economics and

Management, Changsha University

of Science and Technology,

Changsha, Hunan 410076, P.R. China

Full list of author information is

available at the end of the article

\begin{abstract}
In this paper, we use variational methods to investigate the solutions of impulsive differential equations on the half-line. The conditions for the existence and multiplicity of solutions are established. The main results are also demonstrated with examples.
\end{abstract}

Keywords: variational methods; impulsive differential equations; boundary value problem; half-line

\section{Introduction}

Impulsive differential equations arising from the real world describe the dynamics of processes in which sudden, discontinuous jumps occur. Such processes are naturally seen in biology, medicine, mechanics, engineering, chaos theory and so on. Due to their significance, a great deal of work has been done in the theory of impulsive differential equations [1-8].

In this paper, we consider the following second-order impulsive differential equations on the half-line:

$$
\left\{\begin{array}{l}
-u^{\prime \prime}(t)+u(t)=\mu f(t, u(t)), \quad t \neq t_{j}, \text { a.e. } t \in[0,+\infty) \\
-\Delta u^{\prime}\left(t_{j}\right)=I_{j}\left(u\left(t_{j}\right)\right), \quad j=1,2, \ldots, n, \\
u^{\prime}(0)=0, \quad u^{\prime}(+\infty)=0
\end{array}\right.
$$

where $0=t_{0}<t_{1}<t_{2}<\cdots<t_{n}<\infty, \Delta u^{\prime}\left(t_{j}\right)=u^{\prime}\left(t_{j}^{+}\right)-u^{\prime}\left(t_{j}^{-}\right)$for $u^{\prime}\left(t_{j}^{ \pm}\right)=\lim _{t \rightarrow t_{j}^{ \pm}} u^{\prime}(t), j=$ $1,2, \ldots, n, u^{\prime}(+\infty)=\lim _{t \rightarrow+\infty} u^{\prime}(t)$.

In recent years, boundary value problems (BVPs) for impulsive differential equations in an infinite interval have been studied extensively and many results for the existence of solutions, positive solutions, multiple solutions have been obtained [9-12]. The main methods used for the infinite interval problems are upper and lower solutions techniques, fixed point theorems and the coincidence degree theory of Mawhin in a special Banach space. On the other hand, many researchers used variational methods to study the existence of solutions for impulsive boundary value problems on the finite intervals [13-19].

However, to the best of our knowledge, the study of solutions (in particular the multiplicity of solutions) for impulsive boundary value problems on the half-line using a varia- 
tional method has received considerably less attention. In [20], Chen and Sun studied the following equations:

$$
\left\{\begin{array}{l}
-u^{\prime \prime}(t)+u(t)=\lambda f(t, u(t)), \quad t \neq t_{j}, \text { a.e. } t \in[0,+\infty), \\
-\Delta u^{\prime}\left(t_{j}\right)=I_{j}\left(u\left(t_{j}\right)\right), \quad j=1,2, \ldots, l, \\
u^{\prime}\left(0^{+}\right)=g(u(0)), \quad u^{\prime}(+\infty)=0,
\end{array}\right.
$$

where $\lambda$ is a positive parameter. By using a variational method and a three critical points theorem, the authors proved the existence and multiplicity of solutions for IBVP (1.2).

Motivated by the above work, in this paper we use critical point theory and variational methods to investigate the existence and multiple of solutions of IBVP (1.1), in particular, its multiple solutions generated from the impulsive. Here, a solution for problem (1.1) is said to be generated from the impulsive if this solution emerges when the impulsive is not zero, but disappears when the impulsive is zero. For example, if problem (1.1) possesses at most one solution when the impulsive is zero, but it possesses three solutions when the impulsive is not zero, then problem (1.1) has at least two solutions generated from the impulsive. Our method is different from problem (1.2) and the main results extend the study made in [20].

\section{Preliminaries and statements}

Firstly, we introduce some notations and some necessary definitions.

Suppose that

$$
V=\left\{u:[0,+\infty) \rightarrow R \text { is absolutely continuous, } u^{\prime} \in L^{2}[0,+\infty)\right\}
$$

Denote the Sobolev space $X$ by

$$
X=\left\{u \in V: \int_{0}^{+\infty}\left(\left|u^{\prime}(t)\right|^{2}+|u(t)|^{2}\right) d t<\infty\right\}
$$

In the Sobolev space $X$, consider the inner product

$$
(u, v)=\int_{0}^{+\infty}\left(u^{\prime}(t) v^{\prime}(t)+u(t) v(t)\right) d t
$$

inducing the norm

$$
\|u\|=\left(\int_{0}^{+\infty}\left(\left|u^{\prime}(t)\right|^{2}+|u(t)|^{2}\right) d t\right)^{\frac{1}{2}}
$$

Obviously, $X$ is a reflexive Banach space.

Let $Y=\left\{u \in C[0,+\infty): \sup _{t \in[0,+\infty)}|u(t)|<+\infty\right\}$, with the norm $\|u\|_{\infty}=\max _{t \in[0,+\infty)}|u(t)|$. Then $Y$ is a Banach space. In addition, $X$ is continuously embedded in $Y$, then there exists a constant $M>0$ such that

$$
\|u\|_{\infty} \leq M\|u\| \quad \text { for all } u \in X .
$$


Suppose that $u \in C[0,+\infty)$. Moreover, assume that for every $j=0,1, \ldots, n-1, u_{j}=$ $\left.u\right|_{\left(t_{j}, t_{j+1}\right)}$ belongs to $C^{2}\left(t_{j}, t_{j+1}\right)$ and $u_{n}=\left.u\right|_{\left(t_{n},+\infty\right)}$ belongs to $C^{2}\left(t_{n},+\infty\right)$. We say that $u$ is a classical solution of BVP (1.1) if it satisfies the following conditions: $u$ satisfies the first equation of (1.1) a.e. on $[0,+\infty)$; the limits $u^{\prime}\left(t_{j}^{+}\right), u^{\prime}\left(t_{j}^{-}\right), j=1,2, \ldots, n$, exist and the impulsive condition of Eq. (1.1) holds; $u^{\prime}(0), u^{\prime}(+\infty)$ exists, and the boundary conditions in Eq. (1.1) hold.

In order to study problem (1.1), we assume that the following conditions are satisfied:

(H1) There exist $a(t) \in L^{2}[0,+\infty), b(t) \in L[0,+\infty), c \geq 0,0<r<2$, such that

$$
|F(t, u)| \leq b(t)\left(|u|^{r}+c\right), \quad|f(t, u)| \leq a(t)|u|^{r-1} \quad \text { for a.e. } t \in[0,+\infty) \text { and all } u \in R,
$$

where $F(t, u)=\int_{0}^{u} f(t, s) d s$.

For each $u \in X$, consider the functional $\varphi$ defined on $X$ by

$$
\begin{aligned}
\varphi(u) & =\frac{1}{2} \int_{0}^{+\infty}\left(\left|u^{\prime}(t)\right|^{2}+|u(t)|^{2}\right) d t+\sum_{j=1}^{n} \int_{0}^{u\left(t_{j}\right)} I_{j}(s) d s-\mu \int_{0}^{+\infty} F(t, u(t)) d t \\
& =\frac{1}{2}\|u\|^{2}+\sum_{j=1}^{n} \int_{0}^{u\left(t_{j}\right)} I_{j}(s) d s-\mu \int_{0}^{+\infty} F(t, u(t)) d t .
\end{aligned}
$$

In view of (H1), it follows that $|F(t, u)| \leq b(t)\left(|u|^{r}+c\right)$, then $\forall u, v \in X \subset L^{2}[0,+\infty)$, $b(t) \in L[0,+\infty)$, we can conclude that $\varphi$ is well defined, and it is easily verified that $\varphi$ is a Gâteaux derivative functional whose Gâteaux derivative at the point $u \in X$ is the functional $\varphi^{\prime}(u) \in X^{*}$, given by

$$
\begin{aligned}
\left(\varphi^{\prime}(u), v\right)= & \int_{0}^{+\infty}\left(u^{\prime}(t) v^{\prime}(t)+u(t) v(t)\right) d t+\sum_{j=1}^{n} I_{j}\left(u\left(t_{j}\right)\right) v\left(t_{j}\right) \\
& -\mu \int_{0}^{+\infty} f(t, u(t)) v(t) d t
\end{aligned}
$$

for any $v \in X$.

In fact, by (H1), for any $u, v \in X$ and $t \in[0,+\infty)$, it holds that

$$
|f(t, u) v| \leq a(t)|u|^{r-1}|v| \leq\|u\|^{r-1} \frac{a^{2}(t)+|v|^{2}}{2} .
$$

Since $a(t) \in L^{2}[0,+\infty)$ and $v(t) \in L^{2}[0,+\infty)$, by applying (2.3) and Leibniz formula of differentiation, we obtain $\left(\varphi^{\prime}(u), v\right)<+\infty$ for any $v \in X$. That is, $\varphi^{\prime}: X \rightarrow X^{*}$ is well defined on $X$.

Lemma 2.1 If $u \in X$ is a critical point of $\varphi$, then $u$ is a classical solution of IBVP (1.1).

Proof Let $u \in X$ be a critical point of the function $\varphi$, we have

$$
\int_{0}^{+\infty}\left(u^{\prime}(t) v^{\prime}(t)+u(t) v(t)\right) d t+\sum_{j=1}^{n} I_{j}\left(u\left(t_{j}\right)\right) v\left(t_{j}\right)-\mu \int_{0}^{+\infty} f(t, u(t)) v(t) d t=0
$$

for any $v \in X$. 
For any $j \in\{1,2, \ldots, n\}$ and $v \in X$ with $v(t)=0$, for every $t \in\left[0, t_{j}\right] \cup\left[t_{j+1},+\infty\right)$. Then $(2.4)$ implies

$$
\int_{t_{j}}^{t_{j+1}}\left(u^{\prime} v^{\prime}+u v\right) d t=\mu \int_{t_{j}}^{t_{j+1}} f(t, u(t)) v(t) d t
$$

This means, for any $w \in H_{0}^{1}\left(t_{j}, t j+1\right)$,

$$
\int_{t_{j}}^{t_{j+1}}\left(u_{j}^{\prime} w^{\prime}+u_{j} w\right) d t=\mu \int_{t_{j}}^{t_{j+1}} f\left(t, u_{j}(t)\right) w(t) d t
$$

where $u_{j}=\left.u\right|_{\left(t_{j}, t_{j+1}\right)}$. Thus $u_{j}$ is a weak solution of the following equation:

$$
u^{\prime \prime}(t)+u(t)=\mu f(t, u(t))
$$

and $u_{j} \in H_{0}^{1}\left(t_{j}, t_{j+1}\right) \subset C\left[t_{j}, t_{j+1}\right]$.

Let $q(t):=-u(t)+\mu f(t, u(t))$, then (2.5) becomes of the following form:

$$
-u^{\prime \prime}(t)=q(t) \quad \text { on }\left(t_{j}, t_{j+1}\right) .
$$

Then the solution of (2.6) can be written as

$$
u(t)=c_{1}+c_{2} t-\int_{t_{j}}^{t} \int_{t_{j}}^{s} q(w) d w d s, \quad t \in\left(t_{j}, t_{j+1}\right)
$$

where $c_{1}$ and $c_{2}$ are two constants. Then $u_{j}^{\prime} \in C^{2}\left(t_{j}, t_{j+1}\right)$ and $u_{j}^{\prime \prime} \in C\left(t_{j}, t_{j+1}\right)$. Therefore, $u_{j} \in C^{2}\left(t_{j}, t_{j+1}\right)$. By the previous equation, we can easily get that the limits $u^{\prime}\left(t_{j}^{+}\right), u^{\prime}\left(t_{j}^{-}\right)$, $j=1,2, \ldots, n-1, u^{\prime}\left(0^{+}\right)$and $u^{\prime}\left(t_{n}^{-}\right)$exist. On the other hand, choose any $v \in X$ such that $v(t) \equiv 0$ for $t \in\left[0, t_{p}\right]$. Then (2.4) implies

$$
\int_{t_{n}}^{+\infty}\left(u^{\prime} v^{\prime}+u v\right) d t=\mu \int_{t_{n}}^{+\infty} f(t, u(t)) v(t) d t
$$

By a similar argument, we can get that $u_{n}=\left.u\right|_{\left(t_{n},+\infty\right)} \in C^{2}\left(t_{n},+\infty\right)$ and $u^{\prime}\left(t_{n}^{+}\right), u^{\prime}(+\infty)$ exist. Therefore, $u$ satisfies the equation in IBVP (1.1) a.e. on $[0,+\infty)$.

By integrating (2.4), one has

$$
\begin{aligned}
& \int_{0}^{+\infty} u^{\prime} v^{\prime} d t+\int_{0}^{+\infty} u v d t+\sum_{j=1}^{n} I_{j}\left(u\left(t_{j}\right)\right) v\left(t_{j}\right)-\mu \int_{0}^{+\infty} f(t, u(t)) v(t) d t \\
& =\int_{0}^{+\infty}\left[-u^{\prime \prime}+u-\mu f(t, u)\right] v d t+\sum_{j=1}^{n}\left[I_{j}\left(u\left(t_{j}\right)\right)-\Delta\left(u^{\prime}\left(t_{j}\right)\right)\right] v\left(t_{j}\right) \\
& \quad+u^{\prime}(+\infty) v(+\infty)-u^{\prime}(0) v(0)=0 .
\end{aligned}
$$

Since $u$ satisfies the equation in $\operatorname{IBVP}(1.1)$ a.e. on $[0,+\infty)$, by $(2.7)$, one has

$$
\sum_{j=1}^{n}\left[I_{j}\left(u\left(t_{j}\right)\right)-\Delta\left(u^{\prime}\left(t_{j}\right)\right)\right] v\left(t_{j}\right)+u^{\prime}(+\infty) v(+\infty)-u^{\prime}(0) v(0)=0
$$


Next we will show that $u$ satisfies the impulsive conditions in IBVP (1.1). If not, without loss of generality, we assume that there exists $i \in\{1,2, \ldots, n\}$ such that

$$
I_{i}\left(u\left(t_{i}\right)\right)+\Delta\left(u^{\prime}\left(t_{i}\right)\right) \neq 0 .
$$

Let $v(t)=e^{-t} \prod_{j=0, j \neq i}^{n}\left(t-t_{j}\right)$.

Obviously, $v \in X$. By simple calculations, we obtain $v\left(t_{j}\right)=0, j=0,1, \ldots, i-1, i+1, \ldots, n$, $v(+\infty)=0$. Then, by $(2.8)$, we get

$$
\begin{aligned}
& \sum_{j=1}^{n}\left[I_{j}\left(u\left(t_{j}\right)\right)-\Delta\left(u^{\prime}\left(t_{j}\right)\right)\right] v\left(t_{j}\right)+u^{\prime}(+\infty) v(+\infty)-u^{\prime}(0) v(0) \\
& \quad=e^{-t}\left[I_{j}\left(u\left(t_{j}\right)\right)-\Delta\left(u^{\prime}\left(t_{j}\right)\right)\right] \prod_{j=0, j \neq i}^{n}\left(t-t_{j}\right)=0
\end{aligned}
$$

which contradicts (2.9). So $u$ satisfies the impulsive conditions of (1.1).

Thus, (2.8) becomes of the following form:

$$
u^{\prime}(+\infty) v(+\infty)-u^{\prime}(0) v(0)=0
$$

for all $v \in X$. Since $v$ is arbitrary, (2.10) shows that $u^{\prime}(+\infty)=u^{\prime}(0)=0$. Therefore, $u$ is a classical solution of IBYP (1.1).

To this end, we state some basic notions and celebrated results from critical points theory.

Definition 2.1 (see [21]) Let $X$ be a real reflexive Banach space. For any sequence $\left\{u_{k}\right\} \subset X$, if $\left\{\varphi\left(u_{k}\right)\right\}$ is bounded and $\varphi^{\prime}\left(u_{k}\right) \rightarrow 0$ as $k \rightarrow 0$ possesses a convergent subsequence, then we say that $\varphi$ satisfies the Palais-Smale condition (denoted by the P.S. condition for short).

Lemma 2.2 (see [22]) Let $X$ be a real Banach space, and let $\varphi \in C^{\prime}(X, R)$ satisfy the P.S. condition. If $\varphi$ is bounded from below, then

$$
c=\inf _{X} \varphi
$$

is a critical value of $\varphi$.

Definition 2.2 (see [23]) If $X$ is a real Banach space, we denote by $\omega_{X}$ the class of all functionals $\phi: X \rightarrow R$ possessing the following property: if $\left\{u_{n}\right\}$ is a sequence in $X$ converging weakly to $u \in X$ and $\liminf _{n \rightarrow \infty} \phi\left(u_{n}\right) \leq \phi(u)$, then $\left\{u_{n}\right\}$ has a subsequence converging strongly to $u$.

Lemma 2.3 (see [23]) Let $X$ be a separable and reflexive real Banach space; let $\phi: X \rightarrow R$ be a coercive, sequentially weakly lower semicontinuous $C^{1}$ functional, belonging to $\omega_{X}$, bounded on each bounded subset of $X$ and whose derivative admits a continuous inverse 
on $X^{*}$; let $J: X \rightarrow R$ be a $C^{1}$ functional with compact derivative. Assume that $\phi$ has a strict local minimum $x_{0}$ with $\phi\left(x_{0}\right)=J\left(x_{0}\right)=0$. Finally, setting

$$
\alpha=\max \left\{0, \limsup _{\|x\| \rightarrow+\infty} \frac{J(x)}{\phi(x)}, \limsup _{x \rightarrow x_{0}} \frac{J(x)}{\phi(x)}\right\}, \quad \beta=\sup _{x \in \phi^{-1}(0,+\infty)} \frac{J(x)}{\phi(x)}
$$

assume that $\alpha<\beta$. Then, for each compact interval $[a, b] \subset\left(\frac{1}{\beta}, \frac{1}{\alpha}\right)$ (with the conventions $\left.\frac{1}{0}=+\infty, \frac{1}{+\infty}=0\right)$, there exists $\sigma>0$ with the following property: for every $\lambda \in[a, b]$ and every $C^{1}$ functional $\psi: X \rightarrow R$ with compact derivative, there exists $\delta>0$ such that for each $\mu \in[0, \delta]$, the equation $\phi^{\prime}(x)=\lambda J^{\prime}(x)+\mu \psi^{\prime}(x)$ has at least three solutions whose norms are less than $\sigma$.

\section{Main results}

Now we get the main results of this paper.

Theorem 3.1 Suppose that (H1) and $\mu>0$ hold. Then IBVP (1.1) has at least one solution if the following conditions hold:

(H2) The impulsive function $I_{j}$ has sublinear growth, i.e., there exist constants $a_{j}>0$, $b_{j}>0$ and $\gamma_{j} \in[0,1), j=1,2, \ldots, n$, such that

$$
\left|I_{j}(u)\right| \leq a_{j}+b_{j}|u|^{\gamma_{j}} \quad \text { for every } u \in R, j=1,2, \ldots, n .
$$

Proof It follows from conditions (H1), (H2) and (2.2) that

$$
\begin{aligned}
\varphi(u) & \geq \frac{1}{2}\|u\|^{2}-\sum_{j=1}^{n} \int_{0}^{u\left(t_{j}\right)}\left[a_{j}+b_{j}|s|^{\gamma_{j}}\right] d s-\mu \int_{0}^{+\infty} b(t)\left(|u(t)|^{r}+c\right) d t \\
& \geq \frac{1}{2}\|u\|^{2}-\sum_{j=1}^{n}\left[a_{j}\left|u\left(t_{j}\right)\right|+b_{j}\left|u\left(t_{j}\right)\right|^{\gamma_{j}+1}\right]-\mu \int_{0}^{+\infty} b(t) d t \cdot\left(\|u\|_{\infty}^{r}+c\right) \\
& \geq \frac{1}{2}\|u\|^{2}-\sum_{j=1}^{n} a_{j}\|u\|_{\infty}-\sum_{j=1}^{n} b_{j}\|u\|_{\infty}^{\gamma_{j}+1}-\mu \int_{0}^{+\infty} b(t) d t \cdot\left(\|u\|_{\infty}^{r}+c\right) \\
& \geq \frac{1}{2}\|u\|^{2}-M \sum_{j=1}^{n} a_{j}\|u\|-M^{\gamma_{j}+1} \sum_{j=1}^{n} b_{j}\|u\|^{\gamma_{j}+1}-\mu\|b\|_{L^{1}}\left(M^{r}\|u\|^{r}+c\right) .
\end{aligned}
$$

Since $0<r<2,0 \leq \gamma_{j}<1$, the above inequality implies that $\lim _{\|u\| \rightarrow \infty} \varphi(u)=+\infty$. So $\varphi$ is a functional bounded from below.

Next we prove that $\varphi$ satisfies the P.S. condition. Let $\left\{u_{k}\right\}$ be a sequence in $X$ such that $\left\{\varphi\left(u_{k}\right)\right\}$ is bounded and $\varphi^{\prime}\left(u_{k}\right) \rightarrow 0$ as $k \rightarrow \infty$. Then there exists a constant $M_{1}$ such that $\left|\varphi\left(u_{k}\right)\right| \leq M_{1}$. We first prove that $\left\{u_{k}\right\}$ is bounded. From (3.1), we have

$$
\frac{1}{2}\left\|u_{k}\right\|^{2}-M \sum_{j=1}^{n} a_{j}\left\|u_{k}\right\|-M^{\gamma_{j}+1} \sum_{j=1}^{n} b_{j}\left\|u_{k}\right\|^{\gamma_{j}+1}-\mu\|b\|_{L^{1}}\left(M^{r}\left\|u_{k}\right\|^{r}+c\right) \leq \varphi\left(u_{k}\right) \leq M_{1} .
$$

Since $0<r<2,0 \leq \gamma_{j}<1$, and $M>0, \mu>0$, it follows that $\left\{u_{k}\right\}$ is bounded in $X$. From the reflexivity of $X$, we may extract a weakly convergent subsequence that, for simplicity, we 
call $\left\{u_{k}\right\}, u_{k} \rightarrow u$ in $X$. Next, we will verify that $\left\{u_{k}\right\}$ strongly converges to $u$ in $X$. By (2.3), we have

$$
\begin{aligned}
\left(\varphi^{\prime}\left(u_{k}\right)-\varphi^{\prime}(u)\right)\left(u_{k}-u\right)= & \left\|u_{k}-u\right\|^{2}+\sum_{j=1}^{n}\left[I_{j}\left(u_{k}\left(t_{j}\right)\right)-I_{j}\left(u\left(t_{j}\right)\right)\right]\left(u_{k}\left(t_{j}\right)-u\left(t_{j}\right)\right) \\
& -\mu \int_{0}^{+\infty}\left[f\left(t, u_{k}(t)\right)-f(t, u(t))\right]\left(u_{k}(t)-u(t)\right) d t .
\end{aligned}
$$

By $u_{k} \rightarrow u$ in $X$, we see that $\left\{u_{k}\right\}$ uniformly converges to $u$ in $C([0,+\infty))$. So,

$$
\begin{aligned}
& \sum_{j=1}^{n}\left[I_{j}\left(u_{k}\left(t_{j}\right)\right)-I_{j}\left(u\left(t_{j}\right)\right)\right]\left(u_{k}\left(t_{j}\right)-u\left(t_{j}\right)\right) \rightarrow 0, \\
& \int_{0}^{+\infty}\left[f\left(t, u_{k}(t)\right)-f(t, u(t))\right]\left(u_{k}(t)-u(t)\right) d t \rightarrow 0 \quad \text { as } k \rightarrow \infty .
\end{aligned}
$$

By $\lim _{k \rightarrow \infty} \varphi^{\prime}\left(u_{k}\right)=0$ and $u_{k} \rightarrow u$, we have

$$
\left(\varphi^{\prime}\left(u_{k}\right)-\varphi^{\prime}(u)\right)\left(u_{k}-u\right) \rightarrow 0 \quad \text { as } k \rightarrow \infty .
$$

In view of (3.2), (3.3) and (3.4), we obtain $\left\|u_{k}-u\right\| \rightarrow 0$ as $k \rightarrow \infty$. Then $\varphi$ satisfies the P.S. condition. According to Lemma 2.2, $\varphi$ has at least one critical point, i.e., IBVP (1.1) has at least one classical solution for $\mu>0$.

Theorem 3.2 Suppose that (H1) and the following conditions hold, then there exist constants $\delta>0, \sigma>0$ such that for each $\mu \in[0, \delta], I B V P(1.1)$ possesses at least three solutions, and their norms are less than $\sigma$. Moreover, two of them are generated from the impulsive.

(H3) $f(t, u)$ is nonincreasing about $u$ for all $t \in[0,+\infty)$.

(H4) There exists a constant $\xi>0$ such that $-6 \sum_{j=1}^{n} \int_{0}^{\xi} I_{j}(s) d s>\xi^{3}$.

(H5) $\max \left\{I^{0}, I^{\infty}\right\}<\delta_{j}, 0<2 M \sum_{j=1}^{n} \delta_{j}<1$, where

$$
I^{0}=\limsup _{u \rightarrow 0} \frac{-\int_{0}^{u} I_{j}(s) d s}{|u|^{2}}, \quad I^{\infty}=\limsup _{|u| \rightarrow \infty} \frac{-\int_{0}^{u} I_{j}(s) d s}{|u|^{2}} .
$$

Proof We apply Lemma 2.3 to prove this theorem.

Firstly, we denote that

$$
\phi(u)=\frac{1}{2}\|u\|^{2}, \quad \psi(u)=\int_{0}^{+\infty} F(t, u) d t, \quad J(u)=-\sum_{j=1}^{n} \int_{0}^{u\left(t_{j}\right)} I_{j}(s) d s
$$

then $\varphi(u)=\phi(u)-J(u)-\mu \psi(u)$.

Now, we show that the fundamental assumptions are satisfied. Obviously, $X$ is a separable and reflexive real Banach space. It is easy to see that $\phi(u)$ is a $C^{1}$ functional, coercive, bounded on each bounded subset of $X, \phi(u)$ belongs to $\omega_{X}$. Suppose that $\left\{u_{n}\right\} \subset X, u_{n} \rightarrow u$ in $X$, then $u_{n}$ converges uniformly to $u$ on $[0, T]$ with $T \in(0,+\infty)$ an arbitrary constant and $\liminf _{n \rightarrow+\infty}\left\|u_{n}\right\| \geq\|u\|$. Thus

$$
\liminf _{n \rightarrow+\infty} \phi\left(u_{n}\right)=\liminf _{n \rightarrow+\infty} \frac{1}{2}\left\|u_{n}\right\|^{2} \geq \frac{1}{2}\|u\|^{2}=\phi(u) .
$$


Therefore, $\phi$ is sequentially weakly lower semicontinuous. For any $u, v \in X$, we have

$$
\begin{aligned}
& \left(\phi^{\prime}\left(u_{k}\right)-\phi^{\prime}(u), u-v\right) \\
& \quad=\int_{0}^{+\infty}\left(u^{\prime}(t)-v^{\prime}(t)\right)\left(u^{\prime}(t)-v^{\prime}(t)\right) d t+\int_{0}^{+\infty}(u(t)-v(t))(u(t)-v(t)) d t \\
& =\|u-v\|^{2} .
\end{aligned}
$$

So $\phi^{\prime}$ is uniformly monotone. By [24], we know that $\left(\phi^{\prime}\right)^{-1}$ exists and is continuous on $X^{*}$.

For any $u \in X$, we have $\left(J^{\prime}(u), v\right)=-\sum_{j=1}^{n} I_{j}\left(u\left(t_{j}\right)\right) v\left(t_{j}\right)$. Suppose that $u_{n} \rightarrow u \in X$, then $u_{n} \rightarrow u$ on $C^{\prime}[0,1]$. By $I_{j} \in C(R, R)$, we have $J^{\prime}\left(u_{n}\right) \rightarrow J^{\prime}(u)$ as $n \rightarrow+\infty$. So $J^{\prime}$ is strongly continuous which implies $J^{\prime}$ is a compact operator by [24].

From the continuity of $f(t, u)$, we can obtain that $f\left(t, u_{n}\right)$ converges uniformly to $f(t, u)$ as $n \rightarrow+\infty$. That is, $\psi^{\prime}\left(u_{n}\right) \rightarrow \psi^{\prime}(u)$ as $n \rightarrow+\infty$. So $\psi^{\prime}$ is strongly continuous on $X$, which shows that $\psi^{\prime}$ is a compact operator by [24]. Moreover, $\psi^{\prime}$ is continuous since it is strongly continuous. In addition, $\phi$ has a strict local minimum 0 with $\phi(0)=J(0)=0$.

Therefore, all the fundamental assumptions hold.

Next we show that $\alpha<1<\beta$.

From (H5), there exist $0<\rho_{1}<\rho_{2}$ such that

$$
-\int_{0}^{u} I_{j}(s) d s \leq \delta_{j}|u|^{2} \quad \text { for }|u| \in\left[0, \rho_{1}\right) \cup\left(\rho_{2},+\infty\right) .
$$

By the continuity of $I_{j}, j=1,2, \ldots, n$, we know that $-\int_{0}^{u} I_{j}(s) d s$ is bounded for any $|u| \in$ $\left[\rho_{1}, \rho_{1}\right]$. One can choose $d_{j}>0, j=1,2, \ldots, n$, and $k>2$ such that

$$
-\int_{0}^{u} I_{j}(s) d s \leq \delta_{j}|u|^{2}+d_{j}|u|^{k} \quad \text { for any }|u| \in R
$$

Then, for any $u \in X$, we have

$$
\begin{aligned}
J(u) & =-\sum_{j=1}^{n} \int_{0}^{u\left(t_{j}\right)} I_{j}(s) d s \leq \sum_{j=1}^{n} \delta_{j}|u|^{2}+\sum_{j=1}^{n} d_{j}|u|^{k} \\
& \leq \sum_{j=1}^{n} \delta_{j}\|u\|_{\infty}^{2}+\sum_{j=1}^{n} d_{j}\|u\|_{\infty}^{k} \leq M\left(\sum_{j=1}^{n} \delta_{j}\|u\|^{2}+\sum_{j=1}^{n} d_{j}\|u\|^{k}\right) .
\end{aligned}
$$

Hence, we have

$$
\limsup _{u \rightarrow 0} \frac{J(u)}{\phi(u)} \leq \frac{M\left(\sum_{j=1}^{n} \delta_{j}\|u\|^{2}+\sum_{j=1}^{n} d_{j}\|u\|^{k}\right)}{\|u\|^{2} / 2} \leq 2 M \sum_{j=1}^{n} \delta_{j}<1 .
$$

On the other hand, if $\left|u\left(t_{j}\right)\right| \leq \rho_{2}$, then $-\int_{0}^{u\left(t_{j}\right)} I_{j}(s) d s \leq h_{j}$, where $h_{j}>0, j=1,2, \ldots, n$. If $\left|u\left(t_{j}\right)\right|>\rho_{2}$, then $-\int_{0}^{u\left(t_{j}\right)} I_{j}(s) d s \leq \delta_{j}\left|u\left(t_{j}\right)\right|^{2}$. Then it follows that

$$
J(u)=-\sum_{j=1}^{n} \int_{0}^{u\left(t_{j}\right)} I_{j}(s) d s \leq \sum_{j=1}^{n} h_{j}+\sum_{j=1}^{n} \delta_{j}|u|^{2} \leq \sum_{j=1}^{n} h_{j}+M \sum_{j=1}^{n} \delta_{j}\|u\|^{2} .
$$


Therefore, we have

$$
\limsup _{\|u\| \rightarrow+\infty} \frac{J(u)}{\phi(u)} \leq 2 M \sum_{j=1}^{n} \delta_{j}<1 .
$$

Combining (3.5) with (3.6), we obtain

$$
\alpha=\max \left\{0, \limsup _{\|u\| \rightarrow+\infty} \frac{J(u)}{\phi(u)}, \limsup _{u \rightarrow 0} \frac{J(x)}{\phi(x)}\right\}<1 .
$$

From (H4), one has

$$
\beta=\sup _{u \in \phi^{-1}(0,+\infty)} \frac{J(u)}{\phi(u)} \geq \frac{J\left(u_{0}\right)}{\phi\left(u_{0}\right)} \geq \frac{-\sum_{j=1}^{n} \int_{0}^{\xi} I_{j}(s) d s}{\frac{\xi^{3}}{6}}>1,
$$

where

$$
u_{0}(t)= \begin{cases}\xi, & 0 \leq t \leq \xi \\ 0, & t \geq \xi\end{cases}
$$

Obviously, $u_{0} \in X \cap \phi^{-1}(0,+\infty)$.

Therefore, we obtain $\alpha<1<\beta$.

By Lemma 2.3, we can choose $\lambda=1 \in[a, b]$ such that $[a, b] \subset\left(\frac{1}{\beta}, \frac{1}{\alpha}\right)$, there exists $\sigma>0$ with the following property: for every $f \in C([0,+\infty) \times R, R)$, there exists $\delta>0$ such that for each $\mu \in[0, \delta]$, the equation $\phi^{\prime}(u)=J^{\prime}(u)+\mu \psi^{\prime}(u)$ has at least three solutions in $X$ whose norms are less than $\sigma$. Hence, IBVP (1.1) has at least three solutions in $X$ whose norms are less than $\sigma$.

Now we prove that IBVP (1.1) has at least two solutions generated from the impulsive. In fact, we only need to verify that IBVP (1.1) has at most one solution when $I_{j}=0, j=$ $1,2, \ldots, n$. On the contrary, assume that IBVP (1.1) has at least two distinct solutions $u_{1}, u_{2}$ when $I_{j}=0, j=1,2, \ldots, n$, then $u_{1}, u_{2}$ are critical points of the operator $\varphi$, which implies $\varphi^{\prime}\left(u_{1}\right)=\varphi^{\prime}\left(u_{2}\right)=0$. From (H3), we know that $f(t, u)$ is nonincreasing about $u$ for any $t \in$ $[0,+\infty)$, then

$$
\left(f\left(t, u_{1}(t)\right)-f\left(t, u_{2}(t)\right)\right)\left(u_{1}(t)-u_{2}(t)\right) \leq 0
$$

Hence, one has

$$
\begin{aligned}
0= & \left(J^{\prime}\left(u_{1}\right)-J^{\prime}\left(u_{2}\right), u_{1}-u_{2}\right)=\int_{0}^{+\infty}\left[\left(u_{1}(t)-u_{2}(t)\right)^{2}+\left(u_{1}^{\prime}(t)-u_{2}^{\prime}(t)\right)^{2}\right] d t \\
& -\mu \int_{0}^{+\infty}\left[f\left(t, u_{1}(t)\right)-f\left(t, u_{2}(t)\right)\right]\left(u_{1}(t)-u_{2}(t)\right) d t \\
\geq & \left\|u_{1}-u_{2}\right\|,
\end{aligned}
$$

which implies that $\left\|u_{1}-u_{2}\right\|^{2}=0$, i.e., IBVP (1.1) has at most one solution when the impulsive are zero. Therefore, we obtain that IBVP (1.1) has at least two solutions generated from the impulsive.

This completes the proof. 


\section{Example}

To illustrate how our main results can be used in practice, we present the following example.

Example 4.1 Let $\mu=1$, consider the following problem:

$$
\left\{\begin{array}{l}
-u^{\prime \prime}(t)+u(t)=f(t, u), \quad t \neq t_{j}, t \in[0,+\infty) \\
-\Delta u^{\prime}\left(t_{j}\right)=I_{j}\left(u\left(t_{j}\right)\right), \quad j=1 \\
u^{\prime}(0)=0, \quad u^{\prime}(+\infty)=0
\end{array}\right.
$$

where

$$
I_{1}(u)=1+u^{\frac{1}{3}}(t), \quad f(t, u)= \begin{cases}1-t, & 0 \leq t<1 \\ 0, & t \geq 1\end{cases}
$$

Since $|F(t, u)| \leq 2 a(t)|u|,|f(t, u)| \leq 2 a(t)|u|^{1-1}$ for a.e. $t \in[0,+\infty)$ and all $u \in R$, where

$$
a(t)= \begin{cases}1-t, & 0 \leq t<1 \\ 0, & t \geq 1\end{cases}
$$

$r=1$, with $\int_{0}^{+\infty} a(t) d t=\frac{1}{2}<+\infty$, then it shows that $(\mathrm{H} 1)$ is satisfied.

It is easy to see that the impulsive function $I_{j}$ has sublinear growth, then condition $(\mathrm{H} 2)$ holds.

Applying Theorem 3.1, problem (4.1) possesses at least one solution.

Example 4.2 Let $\mu=1$, consider the following problem:

$$
\left\{\begin{array}{l}
-u^{\prime \prime}(t)+u(t)=f(t, u), \quad t \neq t_{j}, t \in[0,+\infty), \\
-\Delta u^{\prime}\left(t_{j}\right)=I_{j}\left(u\left(t_{j}\right)\right), \quad j=1, \\
u^{\prime}(0)=0, \quad u^{\prime}(+\infty)=0,
\end{array}\right.
$$

where

$$
f(t, u)=\left\{\begin{array}{ll}
\cos t, & 0 \leq t<\frac{\pi}{2}, \\
1, & t \geq \frac{\pi}{2},
\end{array} \quad I_{1}(u)= \begin{cases}-32|u|^{3}, & |u|<1, \\
-32|u|^{\frac{1}{3}}, & |u| \geq 1 .\end{cases}\right.
$$

Suppose that $\xi=\frac{1}{2}$ and $L(u)=\int_{0}^{u} I_{1}(s) d s$, then

$$
L(u)= \begin{cases}-8|u|^{4}, & |u|<1, \\ -24|u|^{\frac{4}{3}}, & |u| \geq 1 .\end{cases}
$$

Obviously, $|F(t, u)| \leq 2 a(t)|u|,|f(t, u)| \leq 2 a(t)|u|^{1-1}$ for a.e. $t \in[0,+\infty)$ and all $u \in R$, where

$$
a(t)= \begin{cases}\cos t, & 0 \leq t<\frac{\pi}{2} \\ 1, & t \geq \frac{\pi}{2}\end{cases}
$$

$r=1$, with $\int_{0}^{+\infty} a(t) d t=1<+\infty$. Then it shows that $(\mathrm{H} 1)$ is satisfied. 
It is easy to see that $f(t, u)$ is nonincreasing about $u$ for all $t \in[0,+\infty)$, then (H3) holds. Since

$$
-\int_{0}^{\xi} I_{1}(s) d s=8 \times\left(\frac{1}{2}\right)^{4}=\frac{1}{2}>\frac{1}{48}=\frac{\xi^{3}}{6},
$$

so (H4) holds.

By a simple computation, one has $I^{0}=I^{\infty}=0$, which implies that condition (H5) is satisfied.

Applying Theorem 3.2, problem (4.2) possesses at least three solutions, and two of them are generated from the impulsive.

\section{Competing interests}

The authors declare that they have no competing interests.

\section{Authors' contributions}

$L Y$ and $J \mathrm{~L}$ carried out the proof of the main part of this article, ZL corrected the manuscript, and participated in its design and coordination. All authors have read and approved the final manuscript.

\section{Author details}

'Press, Hunan Normal University, Changsha, Hunan 410081, P.R. China. ${ }^{2}$ Department of Mathematics, Hunan Normal University, Changsha, Hunan 410081, P.R. China. ${ }^{3}$ School of Economics and Management, Changsha University of Science and Technology, Changsha, Hunan 410076, P.R. China.

\section{Acknowledgements}

This work is partially supported by the National Natural Science Foundation of China (No. 71201013), the Humanities and Social Sciences Project of the Ministry of Education of China (No. 12YJC630118), the Innovation Platform Open Funds for Universities in Hunan Province of China (No. 13K059), the Provincial Natural Science Foundation of Hunan (No. 11JJ3012).

\section{Received: 9 July 2013 Accepted: 29 August 2013 Published: 07 Nov 2013}

\section{References}

1. Lakshmikantham, V, Bainov, DD, Simeonov, PS: Theory of Impulsive Differential Equations. World Scientific, Singapore (1989)

2. Samoilenko, AM, Perestyuk, NA: Impulsive Differential Equations. World Scientific, Singapore (1995)

3. Agarwal, RP, Franco, D, O’Regan, D: Singular boundary value problems for first and second order impulsive differential equations. Aequ. Math. 69, 83-96 (2005)

4. Li, J, Nieto, JJ, Shen, J: Impulsive periodic boundary value problems of first-order differential equations. J. Math. Anal. Appl. 325, 226-299 (2007)

5. Chu, J, Nieto, JJ: Impulsive periodic solutions of first-order singular differential equations. Bull. Lond. Math. Soc. 40, 143-150 (2008)

6. Luo, ZG, Shen, JH: Stability and boundedness for impulsive functional differential equations with infinite delays. Nonlinear Anal. 46, 475-493 (2001)

7. Cai, GL, Ge, WG: Positive solutions for second order impulsive differential equations with dependence on first order derivative. J. Math. Res. Expo. 26, 725-734 (2006)

8. Hernandez, E, Henriquez, HR, McKibben, MA: Existence results for abstract impulsive second-order neutral functional differential equations. Nonlinear Anal. TMA 70, 2736-2751 (2009)

9. Tian, Y, Ge, WG: Triple positive solutions of three-point boundary value problem for second-order impulsive differential equations on the half-line. Dyn. Syst. Appl. 17, 637-652 (2008)

10. Liu, XY, Yan, BQ: Multiple solutions of impulsive boundary value problems on the half-line. J. Comput. Appl. Math. 5 111-123 (1998)

11. Guo, DJ: Multiple positive solutions for first order impulsive superlinear integro-differential equations on the half line. Acta Math. Sci. 31, 1167-1178 (2011)

12. Li, JL, Nieto, JJ: Existence of positive solutions for multipoint boundary value problem on the half-line with impulses. Bound. Value Probl. 2009, Article ID 834158 (2009)

13. Nieto, JJ, Regan, DO: Variational approach to impulsive differential equations. Nonlinear Anal. 10, $680-690$ (2009)

14. Nieto, JJ: Variational formulation of a damped Dirichlet impulsive problem. Appl. Math. Lett. 23, 940-942 (2010)

15. Xiao, J, Nieto, JJ, Luo, ZG: Multiplicity of solutions for nonlinear second order impulsive differential equations with linear derivative dependence via variational methods. Commun. Nonlinear Sci. Numer. Simul. 17, 426-432 (2012)

16. Sun, J, Chen, $\mathrm{H}$ : Variational method to the impulsive equation with Neumann boundary conditions. Bound. Value Probl. 17, Article ID 316812 (2009)

17. Sun, J, et al.: The multiplicity of solutions for perturbed second order Hamiltonian systems with impulsive effects. Nonlinear Anal. TMA 72, 4575-4586 (2010)

18. Zhang, Z, Yuan, R: An application of variational methods to Dirichlet boundary value problem with impulses. Nonlinear Anal., Real World Appl. 11, 155-162 (2010) 
19. Tian, Y, Ge, WG: Applications of variational methods to boundary value problem for impulsive differential equations. Proc. Edinb. Math. Soc. 51, 509-527 (2008)

20. Chen, $H$, Sun, J: An application of variational method to second-order impulsive functional differential equation on the half-line. Appl. Math. Comput. 217, 1863-1869 (2010)

21. Mawhin, J, Willem, M: Critical Point Theory and Hamiltonian Systems. Springer, Berlin (1989)

22. Rabinowitz, PH: Variational methods for Hamiltonian systems. In: Handbook of Dynamical Systems, vol. 1, pp. 1091-1127 (2002)

23. Ricceri, B: A further three critical points theorem. Nonlinear Anal. 71, 4151-4157 (2009)

24. Zeidler, E: Nonlinear Functional Analysis and Its Applications. Springer, Berlin (1990)

10.1186/1687-1847-2013-293

Cite this article as: Yan et al.: Existence and multiplicity of solutions for second-order impulsive differential equations on the half-line. Advances in Difference Equations 2013, 2013:293

Submit your manuscript to a SpringerOpen ${ }^{\circ}$ journal and benefit from:

- Convenient online submission

- Rigorous peer review

- Immediate publication on acceptance

Open access: articles freely available online

- High visibility within the field

- Retaining the copyright to your article 